\title{
Diagnostic Efficacy of Uniportal Video-Assisted Thoracoscopic Surgery in Undiagnosed Pleural Effusion
}

\author{
Muharrem Özkaya
}

Department of Thoracic Surgery, Health Sciences University Antalya Practice and Research Center, Antalya, Turkey

\begin{abstract}
Introduction: We aimed to evaluate the diagnostic efficacy of uniportal video-assisted thoracoscopic surgery (VATS) in undiagnosed pleural effusions.

Methods: We examined the medical records of all consecutive patients with undiagnosed pleural effusions who underwent uniportal VATS between 2014 and 2018 at the Health Sciences University Antalya Practice and Research Center. We included 41 males (55.4\%) and 33 females (44.5\%) with a mean age of 64.12 y (range, 35-88y) in the study. VATS was performed under general or local anesthesia according to the patients' performance status. Pleural drainage and/or biopsies were performed through a single lumen with a 1-2 cm incision. A single chest tube was placed from the port entry after the procedure. The chest tube was left in place for a minimum of 3 days and removed when the fluid drainage was less than $100 \mathrm{ml} / 24 \mathrm{~h}$. Patients were discharged the day after chest tube removal and a return visit was scheduled on postoperative day 30 for clinical evaluation and a new chest radiograph.

Results: Pleural cytology was performed in all patients, whereas biopsies were performed in 53 patients (71.6\%). Pathological examination of biopsies demonstrated that $56.6 \%$ of patients had a malignancy of the pleura and $43.4 \%$ had benign pleural diseases, and among them, 3.7\% had tuberculosis. The overall diagnostic yield of VATS in the study was 60/74 (81.0\%). The most common primary lung cancer with the involvement of the pleura was the adenocarcinoma (78.5\%). The most common metastatic tumors originated from the lungs (46.6\%), followed by the breasts (26.6\%). There was no intraoperative mortality. Discussion and Conclusion: Uniportal VATS is well tolerated and safe for the diagnosis and treatment of undiagnosed pleural effusions.

Keywords: Diagnosis; malignant; pleural effusion.
\end{abstract}

A nnually 1.5 million patients suffer from pleural effusions in developed countries ${ }^{[1]}$.

In $20 \%-40 \%$ of the patients with pleural effusions, a diagnosis is not obtained despite repeated thoracentesis and closed pleural biopsy ${ }^{[2]}$. Malignant pleural effusion usually results from the dissemination of metastatic cancers and commonly leads to debilitating symptoms and multiple interventions due to recurrences ${ }^{[3]}$. Uniportal
VATS under sedation or general anesthesia has grown in popularity as a diagnostic and therapeutic tool for undiagnosed exudative pleural effusions. In patients with lowperformance status, VATS under sedation is now widely used in the diagnosis and management of pleural effusions ${ }^{[4-6]}$.

The aim of this study was to evaluate the efficacy of uniportal VATS in undiagnosed pleural effusions.

Correspondence (iletişim): Muharrem Özkaya, M.D. Saglik Bilimleri Universitesi Antalya Uygulama ve Arastirma Merkezi,

Gogus Cerrahisi Anabilim Dali, Antalya, Turkey

Phone (Telefon): +90 5326543438 E-mail (E-posta): drmuharremozkaya@gmail.com

Submitted Date (Başvuru Tarihi): 16.05.2018 Accepted Date (Kabul Tarihi): 26.05.2018

Copyright 2018 Haydarpaşa Numune Medical Journal

This is an open access article under the CC BY-NC license (http://creativecommons.org/licenses/by-nc/4.0/). 


\section{Materials and Methods}

We retrospectively analyzed 74 patients with undiagnosed pleural effusions who underwent uniportal VATS. All procedures were performed in the operating room with patients in full lateral position. At admission, patients underwent complete laboratory assays, blood gas analyses, chest roentgenograms, electrocardiograms, and eventually, chest computed tomography (CT) scans. A written consent was obtained for the uniportal VATS pleural drainage, biopsy, and pleurodesis procedure from each patient. The study was conducted in accordance with the principles of the Declaration of Helsinki. As a retrospective service evaluation, regional ethics approval was not required. Patient-identifiable information was not recorded to maintain patient confidentiality.

In 34 patients, uniportal VATS were performed under general anesthesia with a double-lumen endotracheal tube for ipsilateral lung collapse. Patients were positioned and draped as for a standard posterolateral thoracotomy so that they were turned to a full lateral decubitus position, and the operating table was flexed to widen the intercostal spaces on the operation side. A small anti-decubitus mattress was placed below the dependent hemithorax. The safest point for thoracentesis was planned preoperatively according to the chest radiograph, tomography, or thoracic ultrasound. In most cases, an intersection of the midaxillary line and the fifth or sixth intercostal space was the site of thoracentesis, and eventually, the site of thoracoport entry. A 10.5-mm single thoracoport was used to enter the thorax after a single-skin incision. A 10-mm thoracoscope with a 6-mm working channel was used in the procedure.

Conversely, in 40 patients with low-performance status, uniportal VATS was performed under local anesthesia, sedation, and spontaneous ventilation, and none of them had endotracheal intubation or epidural or nerve block analgesia. Patients were positioned and draped the same way. They were sedated with an individualized combination of midazolam, fentanyl, and propofol. Supplemental oxygen was administered through a mask, and oxygen saturation, electrocardiogram, and blood pressure were monitored. After local anesthesia was obtained with $10 \mathrm{ml}$ lidocaine injected into the planned intercostal space, a thoracentesis was performed from the pleural effusion for biochemical, microbiological, and pathological examination. The position of the trocar was defined with the help of thoracentesis. A 10.5-mm single thoracoport was used to enter the thorax after a single-skin incision. A 10-mm thoracoscope with a 6-mm working channel was used for the procedure. Additional injection of lidocaine was applied to the site of pleural biopsy required for a diagnostic purpose.

In all patients, pleural fluid was evacuated gradually to avoid the risk of re-expansion pulmonary edema. A simple pleural biopsy with cup biopsy forceps through the thoracoscope was performed for the patients with unknown primary cancer and those with pleural nodules or any patient with pleural abnormality. At the end of the procedure, a 32-F single-thorax drain was placed through the thoracoport incision. The chest tube was left in the same place for a minimum of 3 days, and then, removed when fluid drainage was less than $100 \mathrm{ml} / 24 \mathrm{~h}$. Patients were discharged the day after chest-tube removal, and a return visit was scheduled on postoperative day 30 for clinical evaluation and a new chest radiograph. Descriptive statistical methods were used in the data analysis [mean \pm standard deviation (SD) or/and range].

\section{Results}

A total of 74 consecutive patients who underwent uniportal VATS with undiagnosed pleural effusions were enrolled in this study. There were 41 males (55.4\%) and 33 females (44.5\%) with a mean age of 64.12 y (range, 35-88 y). For 51 patients, pleural fluid occurred in the right side and for 23 in the left (Table I).

Overall, VATS pleural biopsies were performed in 53 (71.6\%) patients. Of these biopsies, 30 (56.6\%) samples were malignant, 2 (3.7\%) were granulomatous inflammations, and 21 (39.6\%) were non-specific. No diagnosis other than benign pleural effusion was found in 14 (18.9\%) patients. The overall diagnostic yield of VATS pleural biopsy in the study was $60 / 74(81.0 \%)$. VATS was performed under general anesthesia with a double-lumen endotracheal tube in $34(45.9 \%)$ of the patients. In 40 (54.0\%) patients with low-performance,

Table 1. Characteristics of the study population $(n=74)$

\begin{tabular}{lc}
\hline Variables & Values \\
\hline Age (y), mean \pm SD & 64.12 years \\
Sex, male/female, $\mathrm{n}(\%)$ & $41 / 33(55.4) /(44.5)$ \\
History of malignancy, $\mathrm{n}(\%)$ & $44(59.4)$ \\
$\begin{array}{l}\text { Side of effusion, } \mathrm{n}(\%) \\
\text { Right } \\
\text { Left }\end{array}$ & $51(68.9)$ \\
$\begin{array}{l}\text { Type of anesthesia, } \mathrm{n}(\%) \\
\text { General anesthesia with a } \\
\text { double-lumen endotracheal tube } \\
\text { Local anesthesia, sedation, } \\
\text { and spontaneous ventilation }\end{array}$ & $23(31.0)$ \\
\hline
\end{tabular}


status VATS were being performed with local anesthesia, sedation, and spontaneous ventilation.

Further, 30 (40.5\%) patients with undiagnosed pleural effusion had no history of malignancy. VATS pleural biopsies were performed in 27 patients. Pathological examination revealed the presence of malignant pleural metastasis in pleural specimens in $14(51.8 \%)$ of these patients; VATS was performed under general anesthesia in 10 of these patients and under local anesthesia in 4. Also, pleural biopsy specimens showed granulomas with caseous necrosis in 2 (7.4\%) of these patients. These 2 patients with tuberculosis were referred to the chest clinic for anti-tuberculosis treatment.

Additionally, 44 (59.4\%) patients with undiagnosed pleural effusion had a history of malignancy (14 breast cancers, 12 lung cancer, and 28 other types of malignancies). VATS pleural biopsies were performed in 26 of these patients. Pathological examination revealed the presence of positive findings for malignancy in the pleural biopsy in 16 (61.5\%) of these patients.

The nature of pleural effusion in 21 patients (28.3\%) was malignant and non-malignant in 45 patients $(60.8 \%)$. In patients with malignant effusion, metastatic adenocarcinoma lung $(n=9)$ was the most common malignancy encountered.

There were no intraoperative mortalities and no major complications. Only in 1 (1.3\%) patient, prolonged air leak was observed in the postoperative periods. The duration of postoperative pleural drainage ranged between 3 and 13 days (mean, 3.36 days). The postoperative hospital stay ranged between 3 and 15 days (mean, 5.6 days).

\section{Discussion}

Exudative pleural effusion may remain undiagnosed despite the repeated cyto-biochemical analysis of pleural fluid, and a pleural biopsy for histological confirmation becomes necessary to define the etiology. Carcinoma of any organ can metastasize to the pleura, and the detection of malignant cells in pleural fluid or tissue indicates an advanced malignancy or poor prognosis. Malignant pleural effusion is estimated to affect more than 100.000 persons each year across Europe and 150.000 people in the United States ${ }^{[7,8]}$. Lung cancer is the most common metastatic tumor to the pleura in men and breast cancer in women, and both malignancies together account for $50 \%-65 \%$ of all malignant effusions ${ }^{[9]}$. In our study, we also found that the most common metastatic tumors originated from the lung (46.6\%).

VATS is usually performed under a general anesthesia in an intubated patient in the operating room and requires at least three ports of entry to the thoracic cavity. In contrast to conventional three-port VATS, uniportal VATS has the advantage of a single incision, which minimizes the transmission of infection to the incision line and the infiltration of the tumor to the skin, subcutaneous tissues, and chest wall in cases of malignant diseases, such as mesothelioma [10-14]. In our study, we performed VATS through a single port under general or local anesthesia.

VATS have the advantage of performing a biopsy on suspicious looking pleural lesions and nodules under direct vision. Despite less invasive methods, which are limited in their therapeutic effectiveness as fibrous septa and dense viscous liquid, VATS has the ability to merge pouches, aspirate fibrin debris, and also allow efficient drainage of loculated effusions. In addition, it is possible to carry out chemical pleurodesis simultaneously ${ }^{[3]}$. Especially in the case of a trapped lung, partial decortication to ensure lung expansion can be easily performed. VATS was also found to be a safe, effective, and well-tolerated surgical procedure in patients showing no improvement with initial treatment using fibrinolytics ${ }^{[15]}$.

In our study, the overall diagnostic yield of VATS pleural biopsy in 74 patients with undiagnosed pleural effusion was $81.0 \%$. Similar experiences with thoracoscopy were reported in literature. Authors from England reported a diagnostic sensitivity of $80.3 \%$ in their study that included 102 patients and from India reported a yield of $74.3 \%$ in 35 patients ${ }^{[16,}$ 17]. Also, the diagnostic yield of VATS has been reported to be $82.3 \%$ for cytology-negative exudates with only one significant complication (1.2\% rate) and no deaths ${ }^{[18]}$.

The complication rate of our study was $1.3 \%$. There were no intraoperative mortalities or major complications. Only in $1(1.3 \%)$ patient, prolonged air leak was observed in the postoperative period, and no complications were recorded in preoperative period. None of our patients experienced empyema or acute respiratory failure.

\section{Limitations to the Study}

Our study were retrospective, and therefore, subject to bias. Further, it was conducted at a single center with a small sample size. Data collection was limited by the completeness of the available patient records.

\section{Conclusion}

Uniportal VATS is well tolerated and safe for the diagnosis and treatment of undiagnosed pleural effusions, and this study adds to the substantial data that VATS is the gold standard investigation for the diagnosis of cytology-negative suspected malignant pleural effusions. 
Acknowledgments: This research received no specific grant from any funding agency in the public, commercial, or not-forprofit sectors.

Ethics Committee Approval: All procedures performed in studies involving human participants were in accordance with the ethical standards of the institutional and/or national research committee and the 1964 Helsinki declaration and its later amendments or comparable ethical standards.

Peer-review: Externally peer-reviewed.

Conflict of Interest: None declared.

Financial Disclosure: The authors declared that this study received no financial support.

\section{References}

1. Wang Z, Xu LL, Wu YB, Wang XJ, Yang Y, Zhang J, et al. Diagnostic value and safety of medical thoracoscopy in tuberculous pleural effusion. Respir Med 2015;109:1188-92. [CrossRef]

2. Dhooria S, Singh N, Aggarwal AN, Gupta D, and Agarwal R. A randomized trial comparing the diagnostic yield of rigid and semirigid thoracoscopy in undiagnosed pleural effusions. Respir Care 2014;59:756-64. [CrossRef]

3. Roberts ME, Neville E, Berrisford RG, Antunes G, Ali NJ; BTS Pleural Disease Guideline Group. Management of a malignant pleural effusion: British Thoracic Society pleural disease guideline 2010. Thorax 2010;65 Suppl 2:ii32-40. [CrossRef]

4. Loddenkemper R. Thoracoscopy-state of the art. Eur Respir J 1998;11:213-21. [CrossRef]

5. Danby CA, Adebonojo SA, Moritz DM. Video-assisted talc pleurodesis for malignant pleural effusions utilizing local anesthesia and I.V. sedation. Chest 1998;113:739-42. [CrossRef]

6. Harris RJ, Kavuru MS, Rice TW, Kirby TJ. The diagnostic and therapeutic utility of thoracoscopy. A review. Chest 1995;108:828-41.

7. Bennett R, Maskell N. Management of malignant pleural effusions. Curr Opin Pulm Med 2005;11:296-300. [CrossRef]

8. American Thoracic Society. Management of malignant pleural ef- fusions. Am J Respir Crit Care Med 2000;162:1987-2001. [CrossRef]

9. Sears D, Hajdu SI. The cytologic diagnosis of malignant neoplasms in pleural and peritoneal effusions. Acta Cytol 1987;31:85-97.

10. Alar T, Ozcelik C. Single-incision thoracoscopic surgery of pleural effusions for diagnosis and treatment. Surg Endosc Other Interv Tech 2013;27:4333-6. [CrossRef]

11. Chernow B, Sahn SA. Carcinomatous involvement of the pleura: an analysis of 96 patients. Am J Med 1977;63:695-702.

12. Basso SMM, Mazza F, Marzano B, Santeufemia DA, Chiara GB, Lumachi $F$. Improved quality of life in patients with malignant pleural effusion following videoassisted thoracoscopic talc pleurodesis. Preliminary results. Anticancer Res 2012;32:5131-4.

13. Mineo TC, Sellitri F, Tacconi F, Ambrogi V. Quality of Life and Outcomes after Nonintubated versus Intubated Video-Thoracoscopic Pleurodesis for Malignant Pleural Effusion: Comparison by a Case-Matched Study. J Palliat Med 2014;17:761-8. [CrossRef]

14. Riker D, Sell R. Ultrasound-guided percutaneous biopsy to diagnose indwelling pleural catheter metastasis. J Bronchol Interv Pulmonol 2012;19:165-7. [CrossRef]

15. Bouros D, Antoniou KM, Chalkiadakis G, Drositis J, Petrakis I, Siafakas N. The role of video-assisted thoracoscopic surgery in the treatment of parapneumonic empyema after the failure of fibrinolytics. Surg Endosc 2002;16:151-4. [CrossRef]

16. Hucker J, Bhatnagar NK, al-Jilaihawi AN, Forrester-Wood CP. Thoracoscopy in the diagnosis and management of recurrent pleural effusions. Ann Thorac Surg 1991;52:1145-7. [CrossRef]

17. Mootha VK, Agarwal R, Singh N, Aggarwal AN, Gupta D, Jindal SK. Medical thoracoscopy for undiagnosed pleural effusions: experience from a tertiary care hospital in north India. Indian J Chest Dis Allied Sci 2011;53:21-4.

18. Medford A, Awan Y, Marchbank A, Rahamim J, UnsworthWhite J, Pearson P. Diagnostic and Therapeutic Performance of Video-Assisted Thoracoscopic Surgery (Vats) in Investigation and Management of Pleural Exudates. Ann R Coll Surg Engl 2008;90:597-600. [CrossRef] 